\title{
GPS 在林业生产面积测量中的应用
}

\section{The Application of GPS in Forestry Production Area Surveying \\ 李江朋}

Jiangpeng Li

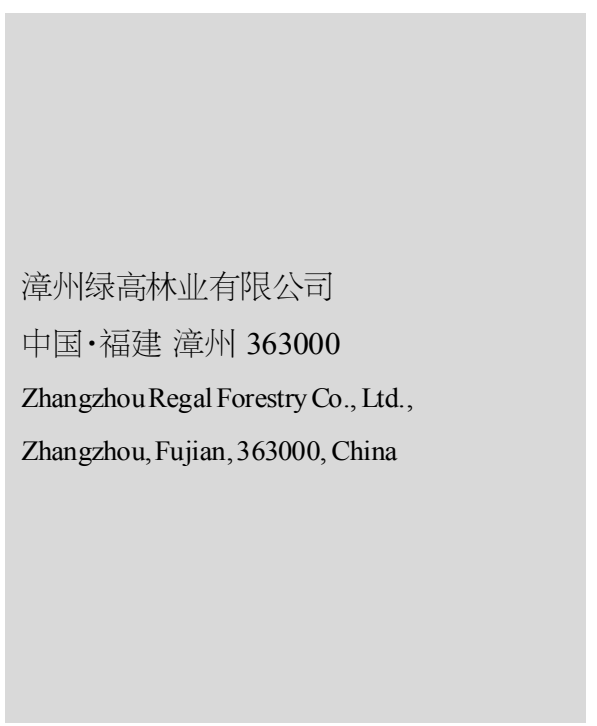

【摘要】随着现代科技的不断进步, GPS 全球定位系统已全面覆盖到各个领域,它的广泛 普及不仅为交通发展带来了便利, 更是在林业生产方面有着很大的优势, 由于它自身具有 定位精度高、观测时间短的特点, 在林业生产面积测绘中起到相当大的作用, 不仅提高了林 业生产的工作效率, 更是给现在林业建设的发展奠定了良好的基础。

【Abstract】Along with the advance of modern science and technology, GPS global positioning system (GPS) has universal coverage to all fields, it is widely spread not only brought convenience for transportation development, but also has great advantage in forestry production, due to its high positioning accuracy, observation time is short, the characteristics of the forestry production area of surveying and mapping plays a considerable role, not only improve the efficiency of the forestry production, but also to the development of forestry construction laid a good foundation.

【关键词】GPS 技术;林业生产;面积测量; 应用

【Keywords \GPS technology; forestry production; area surveying; application

【DOI】10.36012/se.v1i 2.908

\section{1 引言}

GPS 的全称是全球定位系统，它是 20 世纪 70 年代由美 国军方研制的一种子午仪卫星定位系统，经过多年的研究和 试验, 耗费的资金上百亿, 终于在 1994 年, 全球覆盖率高达 98\%的 24 颗 GPS 卫星星座已全面建设完成。伴随着中国高科 技的不断进步以及 GPS 技术在现代林业发展中越来越广泛 的应用, 特别是在林业生产面积测绘工作中如何应用 GPS 技 术是需要分析的问题, 由于 GPS 技术的应用, 在林业生产面 积测绘工作中发挥着极大的作用, 既解放了人力, 还提高了林 业生产工作效率，并且为测绘工作的正确性提供了良好的保 障 ${ }^{[1]}$ 。本文从 GPS 系统的特点、注意事项以及在生产面积测绘 中的应用和怎样使 GPS 技术在林业生产面积测绘工作中发 挥最大的优势几方面来分析。

\section{GPS 的特点}

(1)定位的准确性很高。它的定位精度会随着距离的不断 减小定位精度也随之增高, 并且在工程精密定位中, 误差也比 较小,这是它自身具有的最大的优势。

(2)全天候定位。由于卫星数目分布的面积较广并且具有
一定的规律性, 它可以确保不管在地球上的任何一个地方可 以同时观测到多颗卫星以实现全天候进行连续导航来进行 定位 ${ }^{[2]}$ 。

(3)观测时间短以及操作简便。GPS 系统自从研究出现以 来一直在做不断的完善, 现已经能做到 $20 \mathrm{~km}$ 以内的相对静 态定位用 $15 \mathrm{~min}$ 就可以完成，并且流动站与基准站的距离如 果越小, 则它的观测时间更短, 甚至在应用实时动态定位时, 观测时间只需要几秒就可准确定位。其次, 是它的操作方式, 随着高科技的大面积普及以及测量自动化程度的提高, 它的 应用在生活中也变得越来越普遍, 操作也日渐简单化, 随着 GPS 接收机的不断改进, 它的重量以及体积相比原来更加轻 便,携带也非常方便, 给人们生活以及工作带来了极大便利 [3]。

\section{GPS 在林业生产面积测绘中的应用}

\section{1 样地的定位}

从过去对森林样地的定位方式以及测量工作来看, 都是 通过投人大量的人力资源以及足够多的时间利用地图导向的 方式来进行定位和监测, 得出的结果通常不是很准确, 并且耗 费了大量的人力物力成本, 而 GPS 技术的应用就很好地解决 了这个问题, 它通过设置参照物以及大面积收集样地信息, 用 
建立坐标的方式来完美的体现出样地的准确信息, 达到准确 定位。

\section{2 对预设地块的面积进行测量}

在林业生产中,地理位置的重要性可想而知, 要想在一个 地块发展林业, 就需要对现场地形的状况进行了解,对其面积 进行测量，但在陡坡以及行走艰难的路段运用常规的工程测 量的方法来进行测量, 测量难度是非常大的, 通过 GPS 技术 可以对该地块面积进行围绕测量一圈，将此测量信息导人 GPS 系统中去, 再通过对 GPS 系统的实际操作, 在预设地块 的面积上进行短距离描点, 最后进行连接就是一个圈状, 此面 积就为预设地块面积。同时, 要想林业得到更好的发展, 森林 面积是不可忽视的一部分, 因此, 对森林面积的测量显得尤为 重要, 更是植树造林的重要任务, 以往是通过人力测量进行绘 图的方法对森林面积进行大概规划, 现在运用 GPS 技术提高 了工作效率, 摒弃了之前的繁杂方法, 从测量方法来看显得更 加直接。

\section{3 和无人机相结合进行测量}

目前,大多国家的无人机都是采用 GPS 卫星定位系统与 惯性导航模式相结合的方式进行操作，它的应用给大范围的 林地监测带来了转机, 有的人工操作不了的测量工作就可以 结合定位系统通过无人机进行监测, 给林业生产方面带来高 科技的同时也提高了工作效率。

\section{4 对林地进行管理}

GPS 定位技术的实施可以对林地资源进行实时监控, 通
过定位系统的监测可以看出人为破坏或者自然损毁林地的面 积大小, 如遇到林地损毁的事件时, 就可以采取 GPS 定位系 统进行操作, 对定位系统所监测出的数据进行分析, 从而确定 受损面积,从而达到对林地的有效管理。

\section{4 结语}

GPS 技术的实际应用在中国林业生产发展过程中起到了 至关重要的作用，同时也拉动了中国林业建设行业的经济增 长, 因此, 在以后的林业建设行业中, GPS 的应用只会越来越 广泛。目前, 中国已在森林资源的监测、样地的测量、植树造林 的可行性面积的测量、病虫害防治面积的测量以及林业用地 的管理方面得到了有效的应用，并且取得了很大的成就。因 此, 在未来林业的发展过程中, 中国更是要积极地把 GPS 技 术运用到更多的林业建设领域, 以此来带动中国林业生产建 设的发展事业,并且为国家的建设带来长远的经济效益。

\section{参考文献}

[1]刘裕,张红叶,于春伟.GPS 在林业生产面积测绘中的应用 [J]. 现代农业科技,2010(24):209+212.

[2] 陈义杰,董陈陈,杨晓强,等.GPS 在林业生产面积测绘中的应 用[丁].现代种业,2008(5):52-53.

[3] 杨培凤,任洁.GPS 技术在林业生产面积测绘中的应用实践探 究[J].工程技术(文摘版),2016(2):18 